\title{
Effects of oil exposure and dispersant use upon environmental adaptation performance and fitness in the European sea bass, Dicentrarchus labrax
}

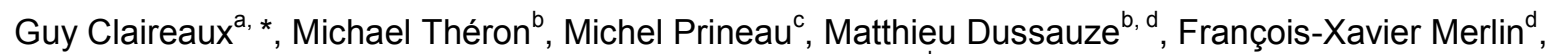 \\ Stéphane Le Floch ${ }^{\mathrm{d}}$ \\ a Université de Bretagne Occidentale, LEMAR (UMR-6539), Unité de Physiologie Fonctionnelle des Organismes \\ Marins, Ifremer - Centre de Brest, Plouzané 29280 France \\ b ORPHY (EA-4324), Université de Bretagne Occidentale, UFR Sciences et Techniques, 6 Avenue Le Gorgeu, \\ Brest 29285-Cedex 3, France \\ ${ }^{c}$ Fédération de Recherche en Environnement pour le Développement Durable (FR-3097), CCA, Allée de l'océan, \\ La Rochelle 17071, France \\ d CEDRE, Service Recherche et Développement, 715 rue Alain Colas, CS 41836, Brest 29218-Cedex 2, France \\ *: Corresponding author : Guy Claireaux, tel.: +33298224938 ; email address : guy.claireaux@univ-brest.fr
}

\begin{abstract}
:
The worldwide increasing recourse to chemical dispersants to deal with oil spills in marine coastal ecosystems is a controversial issue. Yet, there exists no adequate methodology that can provide reliable predictions of how oil and dispersant-treated oil can affect relevant organism or population-level performance. The primary objective of the present study was to examine and compare the effects of exposure to untreated oil (weathered Arabian light crude oil), chemically dispersed oil (Finasol, TOTALFluides) or dispersant alone, upon the ability of fish for environmental adaptation. To reach that goal, we implemented high-throughput, non-lethal challenge tests to estimate individual hypoxia and heat tolerance as surrogate measures of their capacity to face natural contingencies. Experimental populations were then transferred into semi-natural tidal ponds and correlates of individuals' fitness (growth and survival) were monitored over a period of 6 months. In accordance with our stated objectives, the contamination conditions tested corresponded to those observed under an oil slick drifting in shallow waters. Our results revealed that the response of control fish to both challenges was variable among individuals and temporally stable (repeatable) over a 2-month period. Exposure to chemical dispersant did not affect the repeatability of fish performance. However, exposure to oil or to a mixture of oil plus dispersant affected the repeatability of individuals' responses to the experimental challenge tests. At population level, no difference between contamination treatments was observed in the distribution of individual responses to the hypoxia and temperature challenge tests. Moreover, no correlation between hypoxia tolerance and heat tolerance was noticed. During the field experiment, hypoxia tolerance and heat tolerance were found to be determinants of survivorship. Moreover, experimental groups exposed to oil or to dispersant-treated oil displayed significantly lower survival than control or dispersant-exposed groups. Finally, from the four experimental populations tested, the one exposed to chemically dispersed oil presented the lowest growth rate.
\end{abstract}

\section{Highlights}

Fish were exposed to petroleum hydrocarbon and/or dispersants. Environmental adaptation ability was assessed in laboratory. Fish were transplanted in the field. Proxies of Darwinian fitness were assessed.

Keywords: Oil spill ; Dispersant ; Fish ; Temperature ; Hypoxia ; Survival ; Growth ; Environmental adaptation ability ; Darwinian fitness 


\section{Introduction}

For much of their activities, raw materials and food supply, human populations are dependent upon coastal ecosystems and catchment basins of large rivers. As a result, industrial and domestic wastes accumulate in these systems, impacting their biological, economic and social value (Moore et al., 2004). To manage this problem, substantial effort has been devoted to developing methodologies to accurately assess the impacts, and predict the consequences, of chemical contaminants loading upon ecosystem functioning. Using biomarkers, initial objectives were to validate early warning signals that would indicate that organisms have been or are being exposed to toxic compounds or that they are suffering or will suffer impairments of ecological significance (Forbes et al., 2006). Unfortunately, these objectives remain largely unattained, leaving available methodologies incapable of providing detection and useful predictions about how contaminants may influence organisms and populations (Van der Oost et al., 2003; Forbes et al. 2006).

Numerous reasons have been put forward to explain current shortfall of biomarkers to inform about the impact of contaminants upon ecologically, socially and economically relevant levels of biological organization i.e., population, community, and ecosystem (Forbes et al., 2006). These include the difficulty to distinguish between a true early warning signal and a false alarm, the lack of integrated mechanistic basis for interpretation, complicated time- and dose-responses, unclear link to Darwinian fitness, confounding influences of external conditions. While it is recognized that high levels of biological organization are too far removed from the causative toxicological events to be used as early warning signals of environmental stress, these levels are of considerable importance to human activities, economy and well being. Central to the present paper is therefore the need to decipher the links between contaminant exposure and population-level effects.

Recent events show that resorting to chemical dispersants to manage oil spills in coastal environments is a highly controversial matter. At issue is whether the risk of ecological effects to marine species from toxic oil components increases or decreases when oil slicks are dispersed before they reach the shoreline (Fucik, 1994). The main outcome of dispersant use is indeed the transfer of oil from the water surface into the water column. As a result, exposure for surface dwelling and intertidal species is potentially decreased, while it is increased for water-column and benthic organisms. Thus, inherent to the recourse to dispersant is the implicit trade-off among different habitats and species having different ecological, social, and economical values.

Fish comprise water-column and benthic species and they are an ecologically, socially and economically valuable resource. Consequently, fish are pivotal when deciding upon the most appropriate response strategy following an oil spill. Unfortunately, data about the effect of dispersant and dispersant-treated oil upon fish are too sparse to fully inform decisions (Linden, 1975; Getter and Baca, 1984; Gagnon and Holdway, 2000; Cohen et al. 2001; Ramachandrana et al., 2004). In particular there is nearly no information about how these compounds may affect the ability of fish to exploit their habitat and how these impairments may transpose into population or community-level impacts (Depledge, 1993).

The physiology of an animal determines the range of environmental conditions under which it can persist without fitness impairments (Fry, 1947 and 1971; Prosser, 1950; Wikelski and Cook, 2006). Through bioenergetics, traits involved in environmental adaptation have well established ties with determinants of individual fitness such as survival, growth and reproduction (Wikelski and Ricklefs, 2001). This has led to the proposal that these performance traits could be useful indicators of aquatic pollution (Brett, 1958; Sprague, 1971; Rice, 1990; McKenzie et al., 2007) since they would link contaminant exposure to ecologically relevant, population-level impacts (Claireaux and Lefrançois, 2007). In aquatic environments, temperature and oxygenation conditions are subject to large fluctuations and alterations in the ability of fish to face these natural contingencies are believed to directly affect their fitness (Somero, 2005; Mandic et al., 2009). On that basis, the incipient lethal oxygen saturation and upper incipient lethal temperature have been generally thought to be potential biomarkers of fish functional integrity and success in the field (Beitinger and 
McCauley, 1990; Davoodi and Claireaux, 2007; Portner and Knust, 2007; Wang and Overgaard, 2007; Claireaux and Davoodi, 2010).

To address the concern, and inform the decision, over the use of chemical dispersant in coastal waters, we implemented a high-throughput, non lethal method to screen a fish population on the basis of individual incipient lethal oxygen saturation and upper incipient lethal temperature. Experimental fish populations were submitted to an hypoxia and temperature challenge test before, shortly after and 1 month after fish had been exposed to one of four experimental conditions i.e., control, mechanically dispersed oil, dispersant-treated oil and dispersant alone. Following the challenge tests, experimental populations were transferred to the field and correlates of individual fitness (growth and survival) were monitored over a period of 6 months. The relationships between individuals' responses to the challenge tests and their performance under field conditions were examined with the double objective of validating the diagnosis ability of the challenge tests and evaluating their interest for prognosticating the long term consequences of fish population exposure to untreated and dispersant-treated oil. Exposure conditions were assessed by measuring water total petroleum hydrocarbon concentration, while fish contamination status was evaluated through the presence of $\mathrm{PAH}$ in the bile using a semi-quantitative fluorimetric method.

\section{Materials and methods}

\subsection{Animals}

Five hundred juvenile European sea bass (Dicentrarchus labrax) were obtained from a commercial fish farm (Aquastream, Ploemeur, France). These fish were issued from the crossing of 15 females and 20 males which originated either from a several-generation domestication program or from the wild. They were transported to institut français de recherche pour l'exploitation de la mer (Ifremer) rearing facility in Brest, where they were maintained 4 months under natural photoperiod and temperature conditions. As they reached the required size (February 2011), fish were tagged subcutaneously with a passive integrated transponder (PIT-Tag, Ordicam, Rambouillet, France) and transported to nearby centre de documentation, de recherche et d'expérimentations sur les pollutions accidentelles des eaux (CEDRE) where they were held in a $12 \mathrm{~m}^{3}$ tank supplied with aerated, re-circulated and bio-filtered natural sea water. A one-month acclimation period, under natural photoperiod and temperature conditions, was allowed before experiment began. Fish were fed daily with commercial pellets (Le Gouessant, Lamballe, France) and feeding was interrupted at least $24 \mathrm{~h}$ before manipulations and experimentation. One week prior to starting the experiment, fish were lightly anaesthetized using clover oil (1.25 $\mathrm{ml} \mathrm{L}^{-1}$; Omega Pharma, Plélo, France) and measured for standard length $(11.23 \pm 0.12 \mathrm{~cm}$; mean \pm SEM) and mass $(25.31 \pm 21 \mathrm{~g})$. It must be noted that fish handling protocol conformed to in force French government standards and regulations.

\subsection{Experimental protocol}

Fish were attributed at random to four experimental groups labeled CONT $(n=112)$, OIL $(n=95)$, OIL+DISP $(n=104)$ and DISP $(n=97)$. The CONT group was used as control. It was never exposed to chemicals and it allowed us to monitor temporal stability (repeatability) of individual physiological performance. The OIL group was destined to be exposed to mechanically dispersed oil, the OIL+DISP group consisted of fish meant to be exposed to chemically dispersed oil and the DISP group was intended to be exposed to the chemical dispersant alone. Using two environmental challenge tests, individuals' physiological ability for environmental adaptation was assessed approximately 2 weeks before (pre-exposure), within a week after (early post-exposure) and 1 month after (late post-exposure) fish had been exposed (groups OIL, DISP and OIL+DISP), or not exposed (group CONT), to chemicals (Table 1). Fish relative contamination level was assessed via bile fluorescence. Two weeks after the last challenge test was conducted (May 
2011), fish groups were transported by road to a set of experimental tidal ponds located in L'Houmeau (400 km from Brest) to assess and compare their ecological performance (growth and survival) under semi-natural conditions.

\subsection{Chemicals, exposure protocol, water and fish contamination assessment}

The study was conducted using weathered Arabian light crude oil. The weathering process consisted in bubbling air through the oil layer until approximately $10 \%$ of the petroleum mass was lost. Such a treatment of the oil simulated a $12 \mathrm{~h}$ ageing of a slick released at sea (Nordvik, 1995). Our weathered oil contained $54 \%$ of saturated hydrocarbons, $34 \%$ of aromatic hydrocarbons and $12 \%$ of polar compounds. Its API (American Petroleum Institute) gravity was 33.

The oil dispersant used in the current study was a $3^{\text {rd }}$ generation commercial formulation (Finasol; TOTAL Fluides, Paris, France). Its efficiency and acute toxicity was assessed by CEDRE using standard testing and approval procedures (respectively NF.T.90-345 and NF.T.90-349).

Experimental exposure protocol is described in details in Milinkovitch et al. (2011). Briefly, $48 \mathrm{~h}$ before exposure, experimental groups were split in two subgroups and transferred into 8, 300-I polyethylene tanks. These tanks were supplied with open flow and aerated sea water and were regulated at the same temperature than the rearing tank. Exposure tanks were equipped with a custom made mixing system which allowed the full homogenisation of the water column. Exposure started by pouring $20 \mathrm{~g}$ of weathered fuel oil (OIL) and/or $1 \mathrm{~g}$ of dispersant (OIL+DISP and DISP respectively) at the surface of the tanks. Exposure lasted $48 \mathrm{~h}$ during which a close circulation of aerated water was maintained in each tank. Following exposure, fish were briefly bathed in clean sea water before being returned into their initial rearing tank. Control fish (CONT) followed the same procedure but were not exposed to the chemical compounds. At the end of the exposure phase, 10 individuals were sampled from each tank and euthanized by a sharp blow on the head. The gall bladder was quickly excised, put in a microtube (Eppendorf, Hamburg, Germany) and quickly frozen in liquid nitrogen. Gall bladders were then stored at $-80^{\circ} \mathrm{C}$ until analysed.

Total petroleum hydrocarbon concentration ([TPH]; sum of dissolved hydrocarbons + oil droplets) was measured in triplicate (sample volume $100 \mathrm{ml}$ ) from each contamination tank, at the beginning and at the end of the exposure period. Water samples extraction was repeated 3 times using $10 \mathrm{ml}$ of dichloromethane Pestipur quality (Carlo Erba Reactifs, SDS). The combined extracts (organic phases) were then dried by filtering through anhydrous sodium sulphate (pesticide grade). The absorbance of the organic phases was measured using a spectrophotometer at $390 \mathrm{~nm}$ (UVeVis, Unicam, France) as described in Fusey and Oudot (1976).

The presence of $\mathrm{PAH}$ metabolites in the fish bile was assessed with a semi-quantitative fluorimetric method (Aas et al., 2000) using a fluorescence spectrophotometer with a $5 \mathrm{~nm}$ slit width on emission and excitation channels (Jasco FP-6200, Tokyo, Japan). Analyses were performed using two excitation-emission wavelengths i.e., 343-383 nm (four-ringed PAH compounds) and 380-430 nm (benzo[a]pyrene-type metabolites) (Krahn et al., 1984; Lin et al., 1996; Aas et al., 2000).

\subsection{Challenge tests}

To avoid unnecessary stress and additional sources of variation, challenge tests were conducted in the fish rearing tank. These tests were conducted approximately two weeks before exposure to chemicals (pre-exposure), within a week and approximately 1 month after chemical exposure (early and late-post-exposure respectively; Table 1). Water salinity didn't change significantly over the duration of the experiment. However, water temperature was intentionally not controlled and it therefore followed the natural seasonal cycle (Table 1). 


\subsection{Hypoxia challenge test (HCT)}

HCT consisted in a rapid decrease in water oxygenation (from nearly $100 \%$ to $20 \%$ air saturation in about one hour) followed by a much slower descent (approximately $2 \%$ air saturation per hour) until the experiment ended (Fig.1 top panel). Ambient oxygenation was controlled by bubbling nitrogen in the input of a submersible pump placed in the tank. Nitrogen flow in the pump was manipulated using a controller and solenoid valve connected to a cylinder (Oxy-REG; Loligo Systems, Tjele, Denmark). As fish lost their ability to maintain balance i.e., when the incipient lethal level was reached, they were quickly removed from the experimental arena, identified (pit tag reading) and placed in a fully aerated recovery tank. The corresponding time and oxygenation level (incipient lethal oxygen saturation, ILOS) was also recorded. Challenge ended as the last fish was removed and it must be noted that less than $1 \%$ mortality was observed.

\subsection{Temperature challenge test (TCT)}

A minimum 5-day recovery period was allowed between HCT and TCT. TCT consisted in a period of rapid temperature increase (from acclimation to $27^{\circ} \mathrm{C}$ in about 2.5 hours) followed by a slower increase (approximately $0.5{ }^{\circ} \mathrm{C}$ per hour) until the experiment ended (Fig. 1 bottom panel). Water temperature was control using a 2500 w heater (JULABO, Seelbach, Germany). A submersible pump placed in the tank ensured water homogeneity and air saturation was maintained via strong air bubbling. As fish lost equilibrium, they were quickly removed from the tank, identified (pit tag reading) and placed in a recovery tank at acclimation temperature. The corresponding time and temperature (upper incipient lethal temperature, UILT) was also recorded. As for HCT, less than 1 $\%$ mortality was recorded in the days that followed TCT.

\subsection{Fish performance under semi-natural conditions}

On May $15^{\text {th }} 2011$, fish were transported to Ifremer field station in L'Houmeau (transportation time: $5 \mathrm{~h}$ ) and distributed among 7 tidal earthen ponds. The characteristics of these ponds have been described on various occasions (Nelson and Claireaux, 2005; Claireaux et al., 2007; Handelsman et al., 2010). Briefly, ponds (area $200 \mathrm{~m}^{2}$; depth 0.8-1.2 m) are connected to the nearby ocean (Bay of Biscay) via a tidal canal. This canal allows natural prey (mainly grass shrimp Palaemonetes varians, common prawn Palaemon serratus and crangonid shrimp Philocheras triptinosus) to arrive at each incoming tide, while standpipes and meshing prevent fish from escaping. Avian predation was avoided by covering the ponds with bird nets. At regular interval (June $17^{\text {th }}$, July $30^{\text {th }}$, August $31^{\text {st }}$ and October $14^{\text {th }} 2011$ ), ponds were drained and fish recovered for individual identification (assessment of survival) and measures of length and mass (calculation of growth). Water temperature and salinity were measured on occasion from day 56 until the experiment was terminated (Conductivity meter 340i, WTW, Weilheim, Germany). Since water conditions were identical in all ponds, these measures were only taken from pond \#4. As the experiment progressed, we noticed that ponds were not strictly identical regarding the vegetation present at the bottom. Moreover, accidental escapes during the monthly draining of the ponds resulted in the partial loss of 3 experimental groups, potentially affecting density-dependant foraging and competing conditions. To limit these sources of inter-ponds variability, at each monthly sampling, fish were randomly reallocated to each pond and the number of ponds used was adjusted accordingly (Table 2).

\subsection{Data analysis and statistics}

Laboratory phase: Pearson's product-moment correlation coefficient was used to assess the repeatability (temporal stability) of individual performance, whereas the coefficient of variation (CV $=$ standard deviation/mean) was used as an index of the extent of inter-individual variation.

Contaminants: PAH metabolites in the bile were analyzed using one way ANOVA followed by post hoc HDS Tukey test. 
Performances during challenge tests: Fish tolerance to challenge tests was analysed following a procedure classically used for survival analysis. For each experimental population (CONT, OIL, OIL+DISP and DISP) the relationship between the percentage of resistance and time was estimated using Kaplan-Meier procedure followed by Cox F-test.

Field survey: When identified, fish that accidentally died or escaped during experimental operations in the field were removed from the data set. Fish growth and survival were analyzed by two way factorial ANOVA with time period and contamination condition as main factors. The relationships between feeding conditions and survival as well as between performance during challenge tests and growth or survival at each time period, were examined using one way ANOVA followed by HDS Tukey post hoc test.

Throughout the manuscript values are given as mean \pm SEM and significance was accepted at $p<$ 0.05. All statistical analyses were performed using Statistica 9 (Stat Soft).

\section{Results}

\subsection{Water contaminants}

Total petroleum hydrocarbon concentration [TPH] was 30-35\% higher in the OIL+DISP tank than in the mechanically dispersed OIL tank. In both cases, however, a similar decrease in [TPH] was observed over the $48 \mathrm{~h}$ exposure period. In the OIL+DISP tank, [TPH] was $73.2 \pm 3.1 \mathrm{mg} \mathrm{l}^{-1}$ at the beginning of the exposure period and $34.2 \pm 1.9 \mathrm{mg}^{-1}(-52 \%)$ at the end. In the OIL tank, [TPH] was $56 \pm 5.2 \mathrm{mg} \mathrm{l}^{-1}$ at the beginning and $26 \pm 2.4 \mathrm{mg} \mathrm{l}^{-1}$ at the end of the exposure period ( $\left.-59 \%\right)$. Petroleum compounds were below detection limits $\left(1 \mathrm{mg} \mathrm{l}^{-1}\right)$ in the DISP and CONT exposure tanks.

\subsection{PAH metabolites in the bile}

At both wavelength tested, the fluorescence of fish bile was found to be significantly influenced by chemical exposure conditions (Fig.2; ANOVA, $p<0.00001$ ). Moreover, a posteriori tests showed that, in both cases, fish from experimental groups OIL and OIL+DISP had significantly higher fluorescence levels than fish from groups CONT and DISP. However, no significant difference between the OIL and OIL+DISP groups was found.

\subsection{Challenge tests}

As exemplified with HTC-3 and TCT-3 (Fig.3), responses to both challenges displayed a noticeable inter-individual variability. Typically, for both challenges a difference of 2-3 $\mathrm{h}$ was found in the time it took to the least tolerant and the most tolerant individuals to lose their ability to maintain equilibrium. This corresponded to incipient lethal oxygen saturation (ILOS) ranging from 9 to $3 \%$ air saturation and to incipient upper lethal temperature (IULT) ranging from 28 to $35^{\circ} \mathrm{C}$. It must be noted, however, that the coefficient of variation (CV) of individual performances was significantly higher for the HCT than for the TCT $(9.03 \pm 0.44$ and $5.97 \pm 0.23$ respectively; $p<0.0001)$. On the other hand, for a given challenge test, no significant difference among trials was observed $(8.41$ \pm 0.38 ; $8.66 \pm 1.08 ; 10.03 \pm 0.58$ for HCT-1 to 3 and $6.02 \pm 0.039 ; 5.34 \pm 0.14 ; 6.57 \pm 0.54$ for TCT-1 to 3 respectively).

Despite this noticeable range of inter-individual variation, examination of the responses of the control fish group (CONT) over time (challenge 1 to 3 ) demonstrated the repeatability of individual performance (time to loss of equilibrium) during HCT and TCT (Table 4). Repeatability of individuals' responses to both challenges was also observed in the DISP group. Individual responses to HCT of fish from the OIL and OIL+DISP groups were also temporally stable. 
However, their response to TCT appeared altered as repeatability was no longer observed 1 month post-contaminant exposure (TCT-3).

The possibility of a trade-off between hypoxia tolerance and heat tolerance was also examined by comparing individuals' ranking in HCT and TCT (Table 4). Surprisingly, a rather similar pattern emerged in all four experimental populations. Whereas no relationship was found between HCT-1 or HCT-2 and TCT-1 or TCT-2, fish performance during TCT-3 was positively correlated with their performances during HCT-1, -2 and -3 .

A non-parametric analysis of time to loss of equilibrium (Kaplan-Meier analysis followed by Cox Ftest) showed no significant difference between experimental groups (Fig.4). However, for both challenge tests, a significant difference in the response curves was observed when trial 1,2 and 3 were compared $(p<0.0001)$. Time required to cull half the fish $\left(T_{50}\right)$ was $494.40 \pm 2.02$ min during HCT-1, $564.71 \pm 2.73$ min during HCT-2 and $398.72 \pm 2.14$ min during HCT-3. Similarly, $\mathrm{T}_{50}$ was $494.45 \pm 1.54$ min during TCT-1, $500.59 \pm 1.53$ during TCT-2 and $423.06 \pm 1.92$ during TCT-3.

\subsection{Field experiment}

Water conditions in the earthen ponds are summarized on Fig.5. Water temperature fluctuated within a range which is quite typical of this type of ecosystem, with the highest recorded value of $25.2{ }^{\circ} \mathrm{C}$ and lowest at $18.3^{\circ} \mathrm{C}$. Salinity also fluctuated $(35.9-40.0 \%)$ but within a range of values that were relatively high compared to normal conditions $(25-30 \%)$. This was due to the fact that to ensure vigorous intra-specific competition for food, prey availability was regulated by controlling tidal water movements into the ponds. As a consequence, water entry did not fully compensate for evaporation, resulting in appreciably high salinity levels.

Fish growth rate varied significantly over the duration of the experiment (ANOVA, $p<0.0001$; Fig. 6 top panel). While fish gained nearly $20 \%$ body weight (BW) during the first monitoring period (P1; May - June), they lost approximately 2, 6 and $5 \%$ BW during periods P2 (June - July), P3 (July August) and P4 (August - October) respectively. Moreover, it was observed that the OIL+DISP fish group experienced significantly lower growth than the other 3 experimental groups (CONT, OIL and DISP; ANOVA, $p<0.01$ ).

Fish survival significantly varied with both the monitoring period and the initial contaminant exposure conditions (ANOVA, $p<0.005$; Fig. 6 bottom panel). Post hoc Tukey-test showed that survival during the second monitoring period was significantly higher than during periods 1 and 3 . Survival during P4 was the even lower than during P2 and P3. Moreover, fish from the OIL+DISP group had significantly lower survival than fish from CONT and DISP groups. However, survival in OIL and OIL+DISP groups was not statistically different.

Growth and survival calculated over the entire experimental period on those fish that were still alive at the end of the survey are also noted on Fig.6 (hatched bars). Fish overall growth was 14.17 $\pm 1.58 \%, 9.45 \pm 3.15 \%, 3.07 \pm 2.30 \%$ and $12.40 \pm 2.48 \%$ BW for group CONT, OIL, OIL+DISP and DISP respectively. Fish overall survival was $22.98 \%, 17.16 \%, 15.77 \%$ and $23.63 \%$ for group CONT, OIL, OIL+DISP and DISP respectively.

Fish performance in the field highlighted an important feature of the natural selection process at work in our experimental ecosystem. When growth rate during the period of optimal feeding condition (P1) was compared in the survivors and non-survivors of periods P2, and P3 (i.e., periods of limited food supply), those that did not survive during these periods had significantly higher growth rate during P1 than those that survived (ANOVA, $p<0.02$; Fig.7). This was no more the case when P4 was examined. However, no significant difference among exposure groups was observed (ANOVA, $p>0.05$; data not shown). 
Individuals' performance during challenge tests were examined from the perspective of their link with proxies of Darwinian fitness namely survival and growth (Fig.8). To conduct this examination, performance during HCT-3 and TCT-3 were used, with the hypothesis that these performances provided a more accurate diagnostic of fishes' physiological status at the time of their transfer into the tidal ponds. When the performance during HCT-3 and TCT-3 of the fish that survived a given period, was compared to that of fish that didn't survive during the same period, we found that during period $\mathrm{P} 1$, fish that died had a significantly lower tolerance to hypoxia and heat than fish that survived. On the other hand, during P2, P3 and P4, survivors and non-survivors could not be distinguished on the basis of their responses to HCT-3 and TCT-3.

\section{Discussion}

\subsection{Contamination conditions}

The objective of the current study was to reproduce conditions were dispersant would be used to treat an oil slick in a coastal environment. Observed water total petroleum hydrocarbon concentration [TPH] did correspond to what has been reported under similar conditions (20 to 60 $\mathrm{mg} \mathrm{I}^{-1}$; Spooner, 1970; Lewis et al., 1998; Lessard and Demarco, 2000). It must be noted, however, that when oil was mechanically dispersed (OIL), observed [TPH] was $66 \%$ of the nominal concentration. This suggests that the mechanical energy allowed the formation of oil droplets in the water but did not avoid oil adherence to tank wall and homogenization system. In the case of dispersant-treated oil, (OIL+DISP), on the other hand, measured concentrations were very close to oil nominal concentration, showing that dispersant lead to the formation of stable, non-adhering droplets.

The semi-quantitative assessment of PAH metabolites level in fish bile yielded to a pattern very similar to that observed in previous experiments (Milinkovitch et al., 2011). Whereas OIL and OIL+DISP displayed the highest fluorescence level, DISP and CONT groups showed a background level corresponding to normal auto-fluorescence of fish bile.

\subsection{Challenges tests}

As observed for other traits of environmental adaptation (Jobling and Baardvik, 1994; Carter et al., 1996; Cooke et al., 2005), our study revealed a significant degree of standing inter-individual variation in sea bass responses to HCT and TCT. The coefficient of variation (CV) is a classical index for assessing the extent of inter-individual variability. In the present experiment, CV of individual responses ranged between 8 and $11 \%$ for HCT and from 5 to $7 \%$ for TCT (Table 3). Although noteworthy, these values are relatively modest compared to what has been reported for other complex traits of physiological performance e.g., growth (20\%; Millot et al., 2008), swimming (15 - $18 \%$; Nelson and Claireaux, 2005; Claireaux et al., 2007; Marras et al., 2010), escape response (22 - $41 \%$; Marras et al., 2011). The fact that our experimental fish were issued from the crossing of 15 females and 20 males, some of which being sampled from the wild, suggests that this narrow range of inter-individual variability is not link to the genetic structure of our experimental fish population. This rather limited inter-individual variation is, however, in line with the view that water oxygenation and temperature are potent determinants of fish physiological performance, and that tolerance to fluctuations in these environmental factors is under severe selection (Webb, 1986; Reznick et al., 2004; Facchin et al., 2009; Domenici, 2009). This view is further strengthened by the fact that in control fish (CONT), responses to both challenge tests were repeatable over a period of 60 days. This temporal stability of incipient lethal oxygen saturation (ILOS) and upper incipient lethal temperature (UILT) is indeed one prerequisite for these traits to be targets for natural selection and evolution (Arnold, 1983; Bolnick et al., 2003; Sears et al., 2009). 
No correlation was found between individual responses to HCT and TCT for challenge 1 and 2 . This result points to the absence of a functional trade-off between ILOS and UILT, and highlights the possibility that hypoxia and heat tolerance may follow independent evolutionary trajectory. However, a significant correlation between individual responses to HCT-3 and TCT-3 was also noticed (Table 4), which contradicts the above hypothesis. We have no explanation for this conflicting observation, but the fact that it was observed in all experimental groups suggests that a seasonal, temperature driven shift in ILOS and UILT may be involved. However, the nature of the underlying mechanisms remains to elucidate.

\subsection{Exposure to contaminants}

Exposure to oil (OIL) and to a mixture of oil and dispersant (OIL+DISP) did not affect the short term repeatability of individual responses to HCT and TCT. In these experimental groups, however, long-term repeatability was affected as no correlation was found between TCT-1 and TCT-3 (Table $4)$. On the other hand, long term repeatability of hypoxia tolerance was observed in these groups (HCT-1 versus HCT-3; Table 4).

Contradicting with individual-level responses is the observation that, 1 week after contaminant exposure (second series of challenges), the overall responses of OIL and OIL+DISP populations were marginally (HCT) or significantly (TCT) different from CONT or DISP populations (Fig.4). However, these differences in population-level responses were no more observed in the third series of challenges (4 weeks post-exposure). This discrepancy between population- and individual-level responses is intriguing but confirms that the effect of an environmental change on individuals' performance is poorly predictable from the mean population result (Nelson, 1989; Nelson et al., 1996). An element of explanation may lie in the interaction between contaminantrelated change in fish performance and the seasonal temperature acclimatization process. Experimental challenge tests indeed spanned over a 2-month period, during which water temperature naturally increased from 13 to $17^{\circ} \mathrm{C}$. This temperature range is associated with the largest thermal sensitivity of sea bass metabolism $\left(Q_{10} \approx 6\right.$; Claireaux and Lagardère, 1999). It could be hypothesized that whereas seasonal conditions set the overall envelop of population response, individual variation in the response to contaminant, and possibly in the seasonal acclimatization process, may affect within population distribution of individual performances. Contradicting with this hypothesis is the report that, following the 4-week acclimation of $12{ }^{\circ} \mathrm{C}$ reared juvenile sea bass to $22{ }^{\circ} \mathrm{C}$, the mean sprint speed of the population increased from 1.7 to $2.0 \mathrm{~m} \mathrm{~s}^{-1}$ without affecting individuals' ranking within that population (Claireaux et al., 2007).

\subsection{Field survey}

Water salinity and temperature in the ponds were irregularly measured. Nevertheless, observed conditions were clearly at the upper limit of sea bass tolerance range. Temperature above 22-24 ${ }^{\circ} \mathrm{C}$ is detrimental to sea bass as it is accompanied by a rapid decrease in aerobic metabolic scope (Claireaux and Lagardère, 1999), impaired cardio-vascular performance (Farrell et al., 2007), reduced growth (Person-Ruyet et al., 2004), reduced swimming performance (Claireaux et al., 2006) and by avoidance behavior (Claireaux and Lefrançois, 2007). Within the salinity range 0 to $30 \%$, the European sea bass is known for having exceptional osmoregulatory capacity e.g., Chatelier et al., (2005). Above $30 \%$, on the other hand, a tight inverse relationship between salinity and survivorship has been reported, $48 \mathrm{~h}$-survival rapidly dropping from $100 \%$ at $30 \%$ to 0 $\%$ at $60 \%$ (Dalla Via et al., 1998). Although not directly measured here, observations suggest that water oxygenation may also have been a determining factor of fish performance in the ponds. On occasion, mullet (Liza sp.) present in adjacent ponds were indeed observed performing aquatic surface respiration. This behavior consists in ventilating the well-oxygenated surface water and it suggests that in these instances at least, water oxygen saturation was below 10-15\% (Lefrançois et al., 2005). 
Survival data clearly confirmed that conditions in the ponds impacted fish performance. During the first period of the field survey (P1), feeding conditions were optimal as illustrated by the nearly 20 $\%$ weight gain observed in all experimental groups (Fig.6). During that period, we observed that fish which performed well during HCT and TCT had significantly better survival then fish that did not (Fig.8). During the subsequent periods (P2 to P4), on the other hand, the culling of hypoxia and heat sensitive individuals, combined with the progressive deterioration of feeding conditions, changed the circumstances of natural of selection, survival being then mostly determined by starvation tolerance. In a recent report is has been shown that individual variation in growth rate in sea bass reflects a trade-off against tolerance of food deprivation (Dupont-Prinet et al., 2010). These authors demonstrated that fast growing individuals have physiological and/or behavioral attributes which lead to larger weight loss when food is not available. Present data clearly support this view by showing that those individuals that experienced fast growth during $\mathrm{P} 1$ were also those that suffered lower survival when trophic conditions deteriorated (P2 to P4; Fig.7).

Fish groups exposed to oil or to chemically dispersed oil suffered poorer growth compared to control or dispersant-exposed groups. Moreover, the OIL+DISP population also endured significantly lower survival rate. These results are largely in line with observations made on the European common sole (Solea solea) using the same set-up of mesocosms (Claireaux et al., 2004). This earlier experiment indeed showed that, 3 months after having been exposed (48 $\mathrm{h}$ ) to heavy fuel oil \#2, contaminated soles displayed reduced survival $(33 \%)$ and growth $\left(0.45 \mathrm{~mm} \mathrm{~d}^{-1}\right)$ compared to control, unexposed individuals (54\% and $0.70 \mathrm{~mm} \mathrm{~d}^{-1}$ respectively). Moreover, after 6 month in the ponds, no sign of recovery was observed, contaminated soles still presenting altered lipid profiles and heavily depressed triacylglycerol to sterol ratios $(0.06$ in the contaminated group versus 2.34 in the control group).

In conclusion, functional physiological bases exist to support the claim that OIL and OIL+DISP fish groups suffered impaired physiological performance and lessened ability to face environmental challenges under natural conditions. Although not observed shortly after exposure to contaminants, these impairments were revealed over time, as fish were exposed to increasingly selective feeding and physico-chemical conditions. Challenge tests did not discriminate experimental groups shortly after contaminant exposure, but they turned to be decisive in deciphering the constraints that occurred under field conditions and their consequences upon determinants of individual fitness such as growth and survival. Experiments are currently being conducted to examine the long-term consequences (<6 months post-exposure) upon fish responses during HCT and TCT. As already demonstrated in rainbow trout (Oncorhynchus mykiss) by Ramachandrana et al., (2004), chemical treatment of oil did not directly affect fish ability for environmental adaptation. However, it contributed to increase exposure to hydrocarbons and therefore increased their detrimental influence upon fish physiology. From the fact that proxies of Darwinian fitness such as survival and growth were affected following exposure to oil and to chemically-treated oil, it would be tempting to speculate that these conditions may interfere with genetic adaptation of sea bass populations. However, trans-generational experiments, including an assessment of population genetic changes, need to be conducted before this point is ascertained.

\section{Acknowledgements}

Authors would like to thank M. Hervy (Ifremer), for providing us with the fish, as well as P. Calves and $\mathrm{M}$. Bonhomme (UBO-Orphy) for their technical assistance. The financial support by Agence National de la Recherche through program ANR-PRECODD-2006, contract ANR-07-ECOT-00401, project DISCOBIOL, is also acknowledged. 


\section{References}

Aas, E., Beyer, J., Goksoyr, A., 2000. Fixed wavelength fluorescence (FF) of bile as a monitoring tool for polyaromatic hydrocarbon exposure in fish: an evaluation of compound specificity inner filter effect and signal interpretation. Biomarkers 5, 9-23.

Arnold, S.J., 1983. Morphology, performance and fitness. Am Zool 23, 347-361.

Beitinger, T.L., McCauley, R.W., 1990. Whole animal physiology processes of the assessment of stress in fish. J Great Lakes Res 16, 542-575.

Bolnick, D.I., Svanback, R., Fordyce, J.A., Yang, L.H., Davis, J.M., Hulsey, C.D., Forister, M.L., 2003. The ecology of individuals: incidence and implications of individual specialization. Am Nat 161, 1-28.

Brett, J.R., 1958. Implications and assessments of environmental stress. In: Larkin, P.A. (Ed.), The Investigation of Fish-Power Problems. Institute of Fisheries, University of British Columbia, Vancouver, BC.

Carter, C.G., Purser, G.J., Houlihan, D.F., Thomas, P., 1996. The effect of decreases ration on feeding hierarchies in groups of greenback flounder (Rhombosolea tapirina). J Mar Biol Ass UK 76, 505-516.

Chatelier, A., McKenzie, D.J., Claireaux, G., 2005. Effects of changes in water salinity upon exercise and cardiac performance in the European sea bass (Dicentrarchus labrax). Mar Biol $147,855-862$.

Claireaux. G., Couturier, C., Groison, A.-L., 2006. Effect of temperature on maximum swimming speed and cost of transport in juvenile European sea bass (Dicentrarchus labrax). J Exp Biol. 209, 3420-3428.

Claireaux, G., Davoodi, F., 2010. Effect of exposure to petroleum hydrocarbons upon the cardiorespiratory function in the common sole (Solea solea). Aquat Toxicol 98, 113-119.

Claireaux, G., Désaunay, Y., Akcha, F., Aupérin, B., Bocquené, G., Budzinski, H., Cravedi, J-P., Davoodi, F., Galois, R., Gilliers, C., Goanvec, C., Guérault, D., Imbert, N., Mazéas, O., Nonnotte, G., Nonnotte, L., Prunet, P., Sebert, P., Véttier, A., 2004. Influence of oil exposure on the physiology and ecology of the common sole Solea solea (L.): experimental and field approaches. Aquat Living Resour 17, 335-352.

Claireaux, G., Handelsman, C., Standen, E., Nelson, J.A., 2007. Thermal and temporal stability of swimming performances in the European sea bass. Physiol Biochem Zool 80, 186-196.

Claireaux, G., Lagardère, J.-P., 1999. Influence of temperature, oxygen and salinity on the metabolism of the european sea bass. J Sea Res 42, 157-168.

Claireaux, G., Lefrançois, C., 2007. Linking environmental variability and fish performance: Integration through the concept of scope for activity. Phil Trans R Soc (B) 362, 2031-2041.

Cohen, A.M., Nugegoda, D., Gagnon, M.M., 2001. The effect of different oil spill remediation techniques on petroleum hydrocarbon elimination in Australian bass Macquaria novemaculeata. Arch. Environ. Contam. Toxicol. 40, 264-270.

Cooke, S.J., Crossin, G.T., Patterson, D.A., English, K.K., Hinch, S.G., Young, J.L., Alexander, R.F., Healey, M.C., Van Der Kraak, G., Farrell, A.P., 2005. Coupling non-invasive physiological assessments with telemetry to understand inter-individual variation in behaviour and survivorship of sockeye salmon: development and validation of a technique. J Fish Biol 67, 1342-1358.

Dalla Via. J., Villani, P., Gasteiger, E., Niederstätter, H., 1998. Oxygen consumption in sea bass fingerling Dicentrarchus labrax exposed to acute salinity and temperature changes: metabolic basis for maximum stocking density estimations. Aquaculture 169, 303-313.

Davoodi, F., Claireaux, G., 2007. Effects of exposure to petroleum hydrocarbons upon the metabolism of the common sole Solea solea. Mar Poll Bull 54, 928-934.

Depledge, M.H., 1993. The rational basis for the use of biomarkers as ecotoxicological tools. In "Nondestructive Biomarkers in Vertebrates" (M. C. Fossi and C. Leonzio, Eds.), pp. 261-285. Lewis, Boca Raton, FL.

Domenici, P., 2009. Escape responses in fish: kinematics, performance and behavior. In Fish Locomotion: An Eco-ethological Perspective (ed. P. Domenici and B.mG. Kapoor), pp. 123170. Enfield: Science Publishers. 
Dupont-Prinet, A., Chatain, B., Grima, L., Vandeputte, M., Claireaux, G., McKenzie, D.J., 2010. Physiological mechanisms underlying a trade-off between growth rate and tolerance of feed deprivation in the European sea bass (Dicentrarchus labrax). J Exp Biol 213, 1143-1152.

Facchin, L., Burgess, HA., Siddiqi, M., Granato, M., Halpern, M.E., 2009. Determining the function of zebrafish epithalamic asymmetry. Phil Trans R Soc (B) 364, 1021-1032.

Farrell, A.P., Axelsson, M., Altimiras, J., Sandblom, E., Claireaux, G., 2007. Maximum cardiac performance and adrenergic sensitivity of the sea bass Dicentrarchus labrax at high temperatures. J Exp Biol 210, 1216-1224.

Forbes, V.E., Palmqvist, A., Bach, L., 2006. The use and misuse of biomarkers in ecotoxicology. Environ Toxicol Chem 25, 272-80.

Fry, F.E.J., 1947. Effect of the environment on animal activity. Univ. Toronto Stud. Biol. Ser. 55, 162.

Fry, F.E.J., 1971. The effect of environmental factors on the physiology of Fish. In: Hoar, W.S., Randall, D.J. (Eds.). Fish Physiology, vol. VI. Academic Press, New York, pp. 1-98.

Fusey, P., Oudot, J., 1976. Comparaison de deux méthodes d'évaluation de la biodégradation des hydrocarbures in vitro. Mater U Organ 4, 241-251.

Fucik, K., 1994. Dispersed Oil Toxicity Tests with Species Indigenous to the Gulf of Mexico." Technical Summary. MMS Publication 94-0021, USA.

Gagnon, M.M., Holdway, D.A., 2000. EROD induction and biliary metabolite excretion following exposure to the water accommodated fraction of crude oil and to chemically dispersed crude oil. Arch. Environ. Contam. Toxicol. 38, 70-77.

Getter, C.D., Baca, B.J., 1984. A laboratory approach for determining the effects of oils and dispersants on mangroves. In: Allen, T.E. (Ed.), Oil Spill Chemical Dispersants: Research, Experience, and Recommendations, STP840. Am. Soc. Testing and Materials, Philadelphia, pp. 5-13.

Handelsman, C., Claireaux, G., Nelson, J.A., 2010. Swimming ability and ecological performance of cultured and wild European sea bass (Dicentrarchus labrax) in coastal tidal ponds. P B Z 83, 435-445.

Jobling M, Baardvik BM (1994). The influence of environmental manipulations on inter- and intraindividual variation in food acquisition and growth performance of Arctic charr, Salvelinus alpinus. J Fish Biol 44: 1069-1087.

Krahn MM, Myers MS, Burrows DG, Malin DC (1984). Determination of metabolites of xenobiotics in the bile of fish from polluted waterways. Xenobiotica 14: 633-646.

Lefrançois C, Shingles A, Domenici P (2005). The effect of hypoxia on locomotor performance and behaviour during escape in Liza aurata. J Fish Biol 67: 1711-1729.

Lessard RR, DeMarco G (2000). The significance of oil spill dispersants. Spill Sci Technol Bull 6: 59-68.

Lewis A, Crosbie A, Davies L, Lunel T (1998). large scale field experiments into oil weathering at sea and aerial application of dispersants. In proceedings of the 21st Arctic and Marine Oil Spill Program (AMOP), Edmonton, Canada.

Lin ELC, Cormier SM, Torsella JA (1996). Fish biliary polycyclic aromatic hydrocarbon metabolites estimated by fixed-wavelength fluorescence: comparison with HPLC-fluorescent detection. Ecotoxicol Environ Saf 35: 16-23.

Linden O (1975). Acute effects of oil and oil/dispersant mixture on larvae of Baltic herring. Ambio 4, $130-133$.

Mandic M, Todgham AE, Richards JG (2009). Mechanisms and evolution of hypoxia tolerance in fish. Proc. R. Soc (B) 276: 735-744.

Marras S, Claireaux G, McKenzie DJ, Nelson JA (2010). Inter-individual variation and repeatability in aerobic and anaerobic swimming performance of the European sea bass (Dicentrarchus labrax; Linnaeus, 1758). J Exp Biol 213: 26-32.

Marras S, Killen SS, Claireaux G, Domenici P, McKenzie DJ (2011). Behavioural and kinematic components of the fast-start escape response in fish: individual variation and temporal repeatability. J Exp Biol 214: 3102-3110.

McKenzie DJ, Garofalo E, Winter MJ, Verweij F, Ceradini S, Day N, van der Oost R, Butler PJ, Chipman J.K., Taylor EW (2007). Complex physiological traits as biomarkers of the sub-lethal toxicological effects of pollutant exposure in fishes. Philos Trans R Soc (B) 362: 2043-2059. 
Milinkovitch T, Godefroy J, Théron M, Thomas-Guyon H (2011). Toxicity of dispersant application: Biomarkers responses in gills of juvenile golden grey mullet (Liza aurata). Environ Poll 159: 2921-2928.

Millot S, Bégout M-L, Person-Le Ruyet J, Breuil G, Di-Poi C, Fievet J, Pineau P, Roue M, Severe A (2008). Feed demand behavior in sea bass juveniles: Effects on individual specific growth rate variation and health (inter-individual and inter-group variation). Aquaculture 274: 87-95.

Moore MN, Depledge MH, Readman JW, Leonard DRP (2004). An integrated biomarker-based strategy for ecotoxicological evaluation of risk in environmental management. Mutation Research 552: 247-268.

Nelson JA (1989). Critical swimming speeds of yellow perch Perca flavescens: comparison of populations from a naturally acidic lake and a circumneutral lake in acid and neutral water. $J$ Exp Biol 145: 239-254.

Nelson JA, Claireaux G (2005). Inter-individual variance of sprint performance, swimming metabolism and endurance in a cohort of European sea bass (Dicentrarchus labrax). Trans Am Fish Soc $134: 1274-1284$.

Nelson JA, Tang Y, Boutilier RG (1996). The effects of salinity change on the exercise performance of two Atlantic cod (Gadus morhua) populations inhabiting different environments. J Exp Biol 199: 1295-1309.

Nordvik AB (1995). The technology windows-of-opportunity for marine oil spill response as related to oil weathering and operations. Spill Sci Tech Bull 2: 17-46.

Person-Le-Ruyet J, Mahé K, Le-Bayon N, Le-Delliou H (2004). Effects of temperature on growth and metabolism in a Mediterranean population of European sea bass, Dicentrarchus labrax. Aquaculture 237: 269-280.

Pörtner HO, Knust R (2007). Climate change affects marine fishes through the oxygen limitation of thermal tolerance. Science 315: 95-97

Prosser CL (1950). Comparative Animal Physiology. 1st edn. Philadelphia and London: W.B. Saunders.

Ramachandrana SD, Hodsona PV, Khana CW, Leeb K (2004). Oil dispersant increases PAH uptake by fish exposed to crude oil. Ecotoxicol Environ Saf 59: 300-308.

Reznick DN, Bryant MJ, Roff D, Ghalambor CK, Ghalambor DE (2004). Effect of extrinsic mortality on the evolution of senescence in guppies. Nature 431: 1095-1099.

Rice JA (1990). Bioenergetics modelling approaches to evaluation of stress in fishes. Am. Fish. Soc. Symp. 8: 90 - 92.

Sears MW, Hayes JP, Banta MR, McCormick D (2009). Out in the cold: physiological capacity influences behaviour in deer mice. Funct Ecol 23: 774-783.

Somero GN (2005). Linking biogeography to physiology: Evolutionary and acclimatory adjustments of thermal limits. Frontiers in Zoology 2:1

Spooner MF 1970. Oil spill in Tarut Bay, Saudi Arabia. Mar Pollut Bull 1: 166-167.

Sprague JB (1971). Measurement of pollutant toxicity to fish. III. Sublethal effects and 'safe' concentrations. Water Res. 5, 245-266.

Van der Oost R, Lopes SSC, Komen H, Satumalay K, van den Bos R, Heida H, Vermeulen NPE (1998). Assessment of environmental quality and inland water pollution using biomarker responses in caged carp (Cyprinus carpio): use of a bioactivation : detoxican ratio as a biotransformation index (BTI). Mar Environ Res 46: 315-319.

Wang T, Overgaard J (2007). The heartbreak of adapting to global warming. Science 315: 49-50.

Webb PW (1986). Locomotion and predator-prey relationship. In Predator-Prey Relationships (ed.

G. V. Lauder and M. E. Feder), pp. 24-41. Chicago: University of Chicago Press.

Wikelski M, Cooke SJ (2006). Conservation physiology. TREE 21, 38 - 46.

Wikelski M, Ricklefs RE (2001). The physiology of life histories. TREE 16, 479-481 
Table 1. Time schedule of the experimental protocol. HCT: hypoxia challenge test; TCT: Temperature challenge test. Prevailing water temperature is given in between parenthesis.

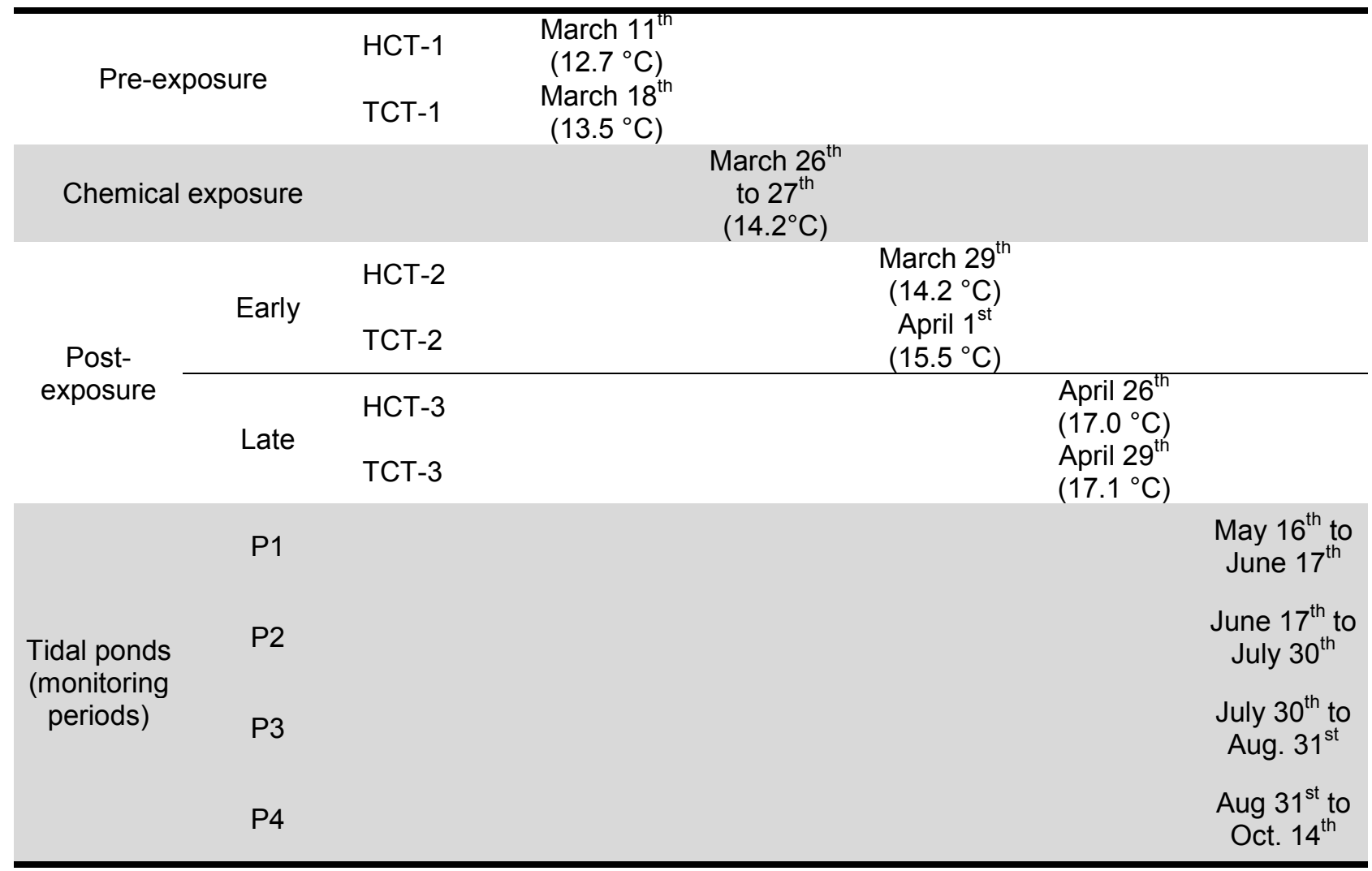


Table 2. Stocking condition in earthen ponds. Composition (\%) of experimental populations and total number of fish in each pond at the start of each monitoring sequence. Empty lines indicate unused ponds (see text for details).

\begin{tabular}{|c|c|c|c|c|c|c|}
\hline & Pond \# & CONT & OIL & OIL+DISP & DISP & Total \\
\hline \multirow{7}{*}{ May $16^{\text {th }}$} & 1 & 26.15 & 24.62 & 24.62 & 24.62 & 65 \\
\hline & 2 & 29.31 & 22.41 & 24.14 & 24.14 & 58 \\
\hline & 3 & 26.15 & 24.62 & 21.54 & 27.69 & 65 \\
\hline & 4 & 29.09 & 25.45 & 23.64 & 21.82 & 55 \\
\hline & 5 & 32.14 & 23.21 & 23.21 & 21.43 & 56 \\
\hline & 6 & 32.20 & 23.73 & 22.03 & 22.03 & 59 \\
\hline & 7 & 26.67 & 23.33 & 21.67 & 28.33 & 60 \\
\hline \multirow{7}{*}{ June $17^{\text {th }}$} & 1 & & & & & \\
\hline & 2 & 28.00 & 20.00 & 18.00 & 34.00 & 50 \\
\hline & 3 & 35.85 & 20.75 & 18.87 & 24.53 & 53 \\
\hline & 4 & 40.91 & 18.18 & 20.45 & 20.45 & 44 \\
\hline & 5 & 27.59 & 25.86 & 24.14 & 22.41 & 58 \\
\hline & 6 & 31.48 & 18.52 & 25.93 & 24.07 & 54 \\
\hline & 7 & 27.59 & 25.86 & 20.69 & 25.86 & 58 \\
\hline \multirow{7}{*}{ July $30^{\text {th }}$} & 1 & & & & & \\
\hline & 2 & 32.00 & 22.00 & 18.00 & 28.00 & 50 \\
\hline & 3 & 36.84 & 18.42 & 21.05 & 23.68 & 38 \\
\hline & 4 & 24.44 & 26.67 & 28.89 & 20.00 & 45 \\
\hline & 5 & 40.48 & 16.67 & 21.43 & 21.43 & 42 \\
\hline & 6 & 23.68 & 18.42 & 18.42 & 39.47 & 38 \\
\hline & 7 & & & & & \\
\hline \multirow{7}{*}{ August $31^{\text {st }}$} & 1 & & & & & \\
\hline & 2 & 36.84 & 18.42 & 21.05 & 23.68 & 38 \\
\hline & 3 & 28.21 & 25.64 & 17.95 & 28.21 & 39 \\
\hline & 4 & 30.56 & 19.44 & 19.44 & 30.56 & 36 \\
\hline & 5 & 31.43 & 14.29 & 17.14 & 37.14 & 35 \\
\hline & 6 & & & & & \\
\hline & 7 & & & & & \\
\hline
\end{tabular}


Table 3. Elements of the distribution of performance (time to loss of equilibrium, min) during hypoxia challenge tests (HCT) and temperature challenge tests (TCT). Min: lowest value; Max: highest value; $\mathrm{CV}$ : coefficient of variation. Numbers in between parenthesis indicate $\mathrm{n}$ values.

\begin{tabular}{|c|c|c|c|c|c|}
\hline & & Mean & Min & Max & CV \\
\hline \multirow{6}{*}{$\begin{array}{c}\text { CONT } \\
(112)\end{array}$} & HCT-1 & 495.28 & 372.83 & 551.00 & 8.04 \\
\hline & НCT-2 & 568.07 & 165.00 & 678.16 & 9.75 \\
\hline & HCT-3 & 400.34 & 293.00 & 476.00 & 10.12 \\
\hline & TCT-1 & 496.39 & 399.00 & 538.83 & 6.01 \\
\hline & TCT-2 & 500.83 & 410.00 & 552.00 & 5.51 \\
\hline & TCT-3 & 427.94 & 211.00 & 486.00 & 7.53 \\
\hline \multirow{6}{*}{$\begin{array}{l}\text { OIL } \\
(95)\end{array}$} & HCT-1 & 500.51 & 372.83 & 548.33 & 7.61 \\
\hline & НCT-2 & 554.54 & 464.00 & 626.00 & 5.70 \\
\hline & НCT-3 & 403.64 & 319.00 & 461.00 & 8.35 \\
\hline & TCT-1 & 498.10 & 418.00 & 538.83 & 5.93 \\
\hline & TCT-2 & 504.10 & 438.00 & 549.10 & 5.55 \\
\hline & TCT-3 & 426.60 & 294.00 & 485.00 & 7.46 \\
\hline \multirow{6}{*}{$\begin{array}{l}\text { OIL+DISP } \\
(104)\end{array}$} & HCT-1 & 494.40 & 375.86 & 546.58 & 9.37 \\
\hline & НСТ-2 & 575.44 & 406.00 & 678.00 & 10.64 \\
\hline & НCT-3 & 403.52 & 318.00 & 470.50 & 10.77 \\
\hline & TCT-1 & 492.99 & 427.00 & 537.33 & 6.01 \\
\hline & TCT-2 & 510.98 & 433.00 & 552.00 & 5.38 \\
\hline & TCT-3 & 426.92 & 336.00 & 479.50 & 5.60 \\
\hline \multirow{6}{*}{$\begin{array}{l}\text { DISP } \\
(97)\end{array}$} & HCT-1 & 489.07 & 383.28 & 551.00 & 8.60 \\
\hline & НCT-2 & 577.10 & 493.00 & 678.16 & 8.56 \\
\hline & HCT-3 & 393.95 & 293.00 & 476.00 & 10.86 \\
\hline & TCT-1 & 496.22 & 399.00 & 538.00 & 6.12 \\
\hline & TCT-2 & 500.73 & 411.00 & 535.20 & 4.92 \\
\hline & TCT-3 & 432.38 & 358.00 & 476.00 & 5.66 \\
\hline
\end{tabular}


Table 4. Matrix of correlations (Pearson correlation coefficient) of performance (time to loss of equilibrium) during hypoxia challenge tests (HCT) and temperature challenge tests (TCT). Challenge- 1 and 2 were 3 weeks apart, challenge- 2 and 3 were 1 month apart (see Table 1). ns indicates non significant relationships $(p>0.05)$.

\begin{tabular}{|c|c|c|c|c|c|c|}
\hline & & HCT-2 & HCT-3 & TCT-1 & TCT-2 & TCT-3 \\
\hline \multirow{5}{*}{ CONT } & HCT-1 & 0.65 & 0.58 & ns & & \\
\hline & HCT-2 & & 0.57 & & ns & \\
\hline & HCT-3 & & & & & 0.21 \\
\hline & TCT-1 & & & & 0.68 & 0.35 \\
\hline & TCT-2 & & & & & 0.37 \\
\hline \multirow{5}{*}{ OIL } & HCT-1 & 0.71 & 0.77 & ns & & \\
\hline & HCT-2 & & 0.72 & & ns & \\
\hline & HCT-3 & & & & & 0.43 \\
\hline & TCT-1 & & & & 0.73 & $\mathrm{~ns}$ \\
\hline & TCT-2 & & & & & ns \\
\hline \multirow{5}{*}{ OIL+DISP } & HCT-1 & 0.71 & 0.60 & ns & & \\
\hline & HCT-2 & & 0.66 & & ns & \\
\hline & HCT-3 & & & & & 0.31 \\
\hline & TCT-1 & & & & 0.77 & $\mathrm{~ns}$ \\
\hline & TCT-2 & & & & & ns \\
\hline \multirow{5}{*}{ DISP } & HCT-1 & 0.75 & 0.66 & ns & & \\
\hline & HCT-2 & & 0.61 & & ns & \\
\hline & HCT-3 & & & & & 0.51 \\
\hline & TCT-1 & & & & 0.68 & 0.49 \\
\hline & TCT-2 & & & & & 0.24 \\
\hline
\end{tabular}


Figure 1. Time course of water oxygenation (top panel) and temperature (bottom panel) during challenge tests. Solid line: Pre-exposure; dashed line: early-post exposure; pointed dashed line: late-post-exposure.
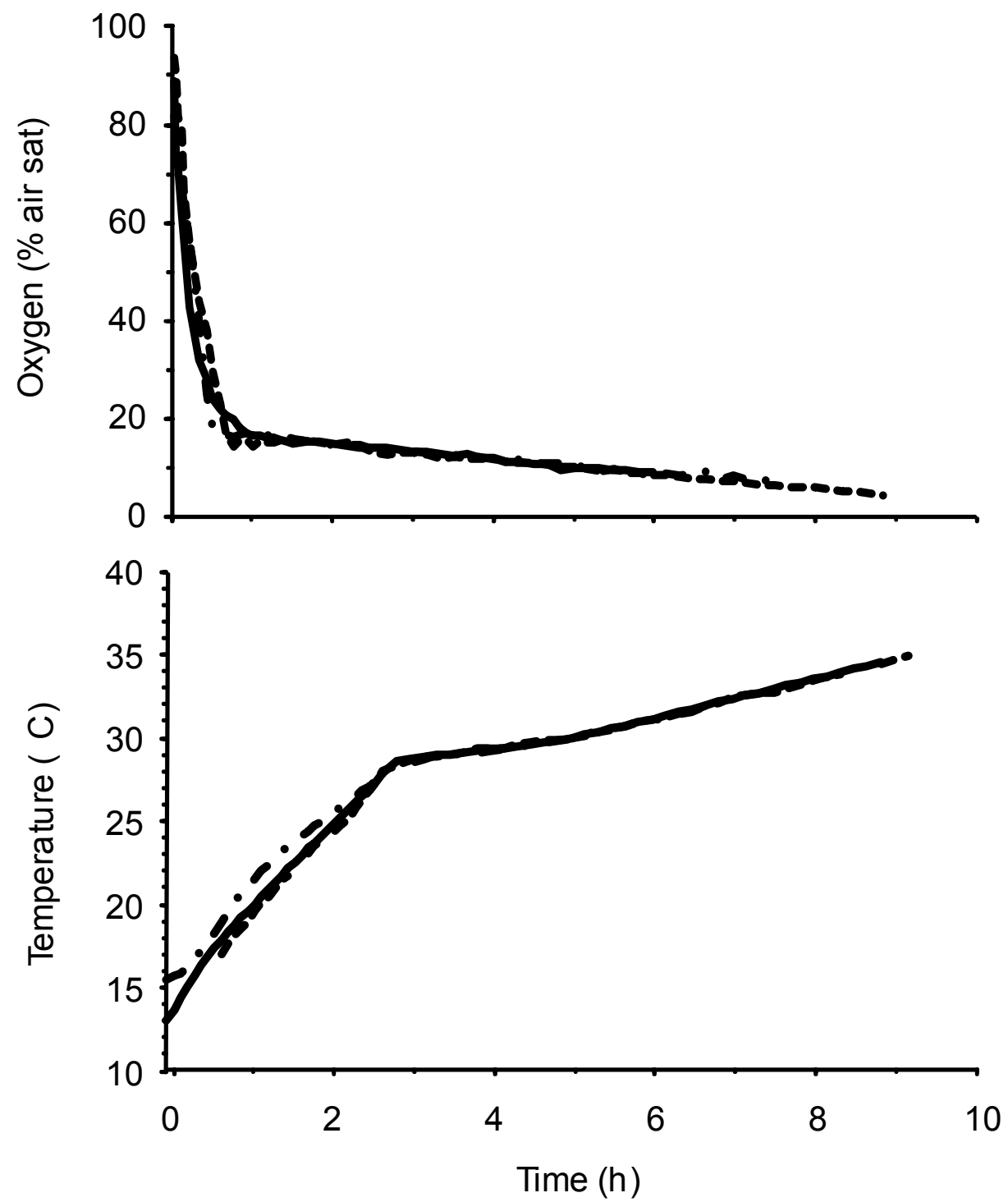
Figure 2. Bile fluorescence (relative arbitrary unit) measured at two wavelengths (top panel: 343$383 \mathrm{~nm}$; bottom panel $380-430 \mathrm{~nm}$ ) in control fish (CONT) as well as in fish exposed to oil (OIL), to a mixture of oil and chemical dispersant (OIL+DISP) or to the dispersant alone (DISP). Different letters in superscript indicate statistically significant difference $(p<0.05)$.
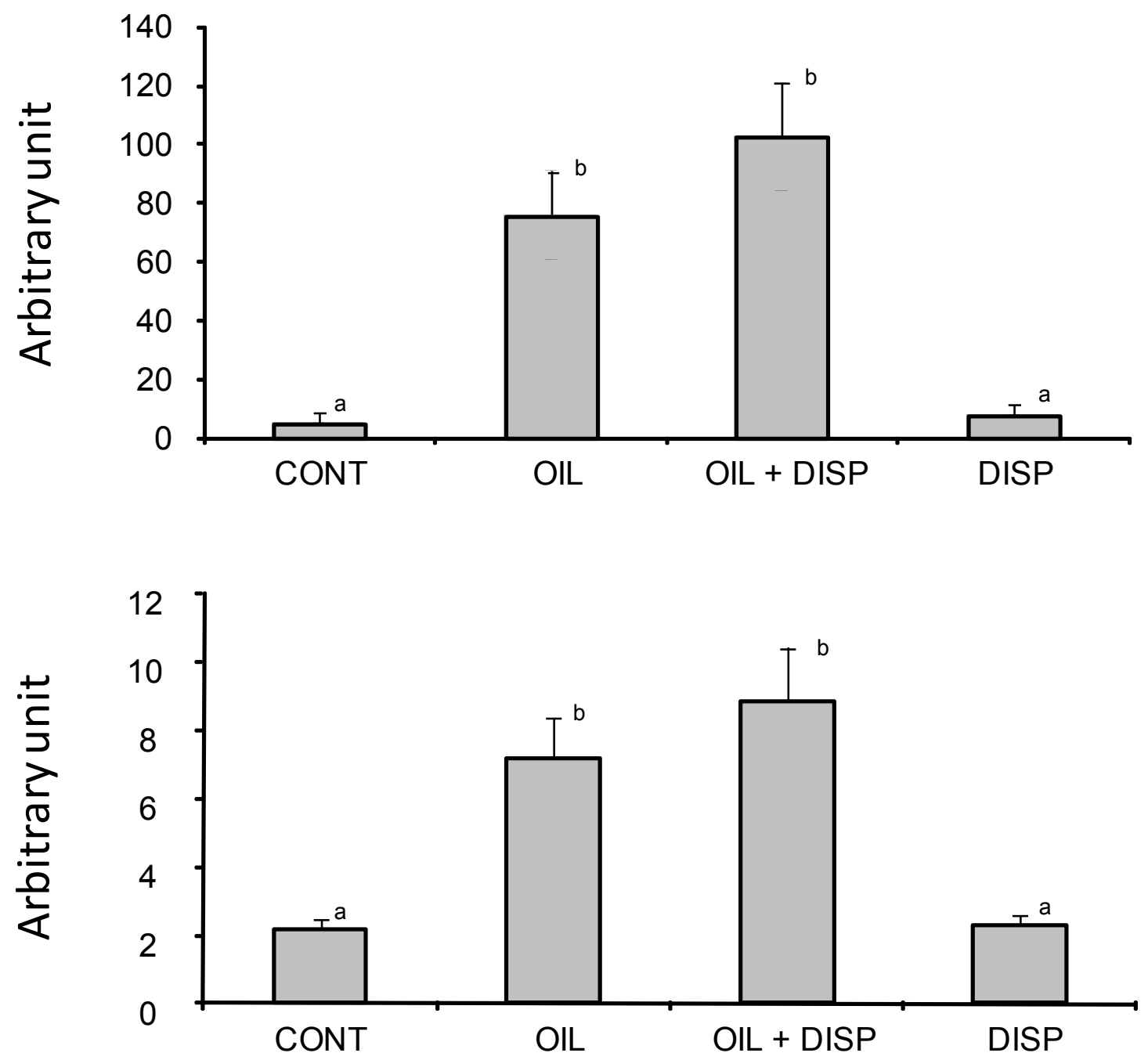
Figure 3. Example of inter-individual variability of time to loss of equilibrium during an hypoxia challenge test (top panel) and temperature challenge test (bottom panel). White bars: CONT; black bars: OIL; dark grey bars: OIL+DISP; light grey bars: DISP. These challenges were conducted on April $26^{\text {th }}$ and $29^{\text {th }}$ (HCT-3 and TCT-3; Table 1).
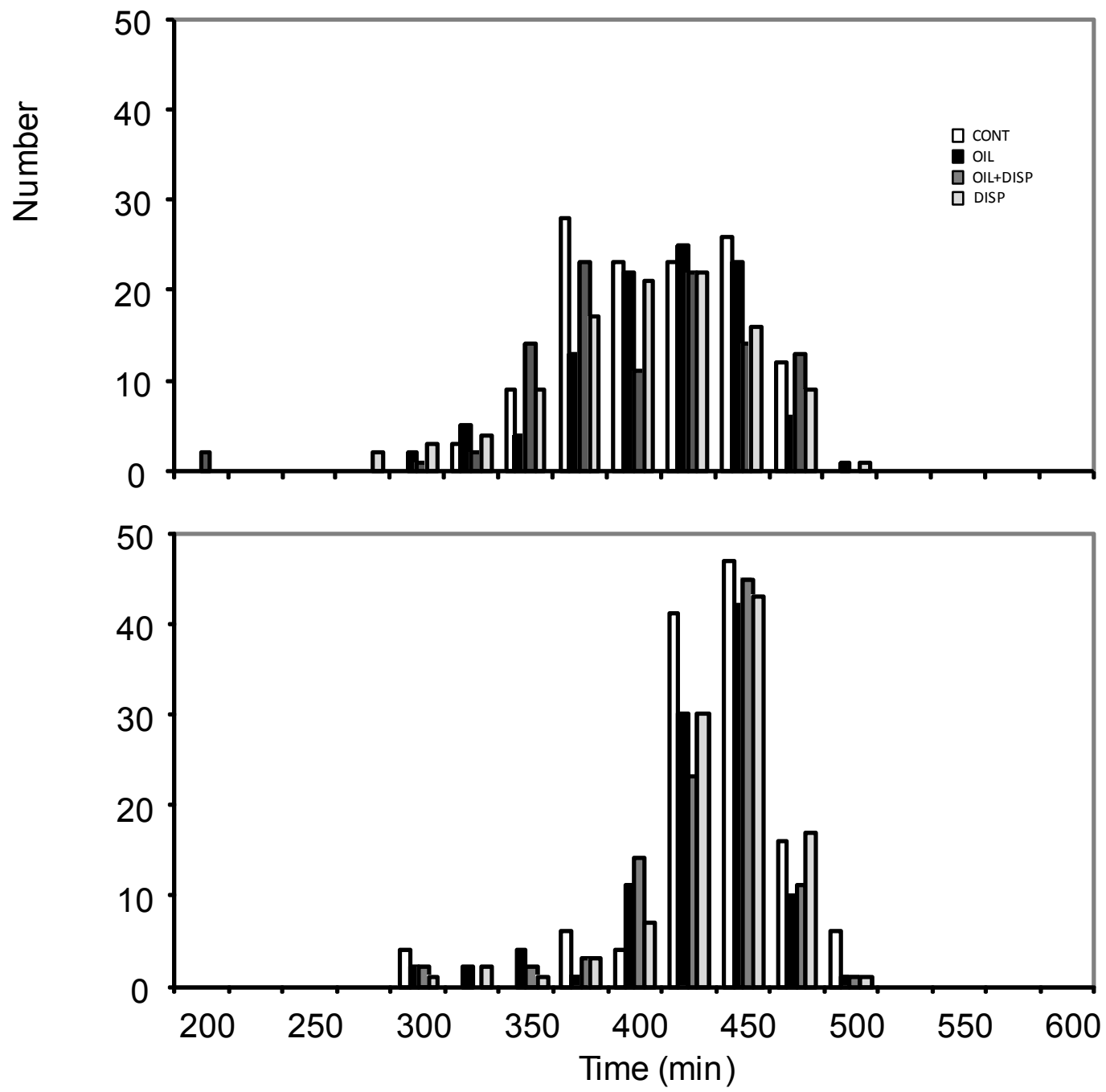
Figure 4. Kaplan-Meier analysis of time to loss of equilibrium during HCT (Fig.4a) and TCT (Fig.4b). A: 2 weeks before exposure to contaminants (HTC: $p=0.19$; TCT: $p=0.58$ ). B: 1 week after exposure to contaminants (HCT: $p=0.07$; TCT: $p<0.000$ ). C: 1 month following contaminants exposure (HCT: $p=0.58$; TCT: $p=0.42$ ). Solid line: CONT; pointed line: OIL; dashed line OIL+DISP; pointed dashed line: DISP.

Figure 4a
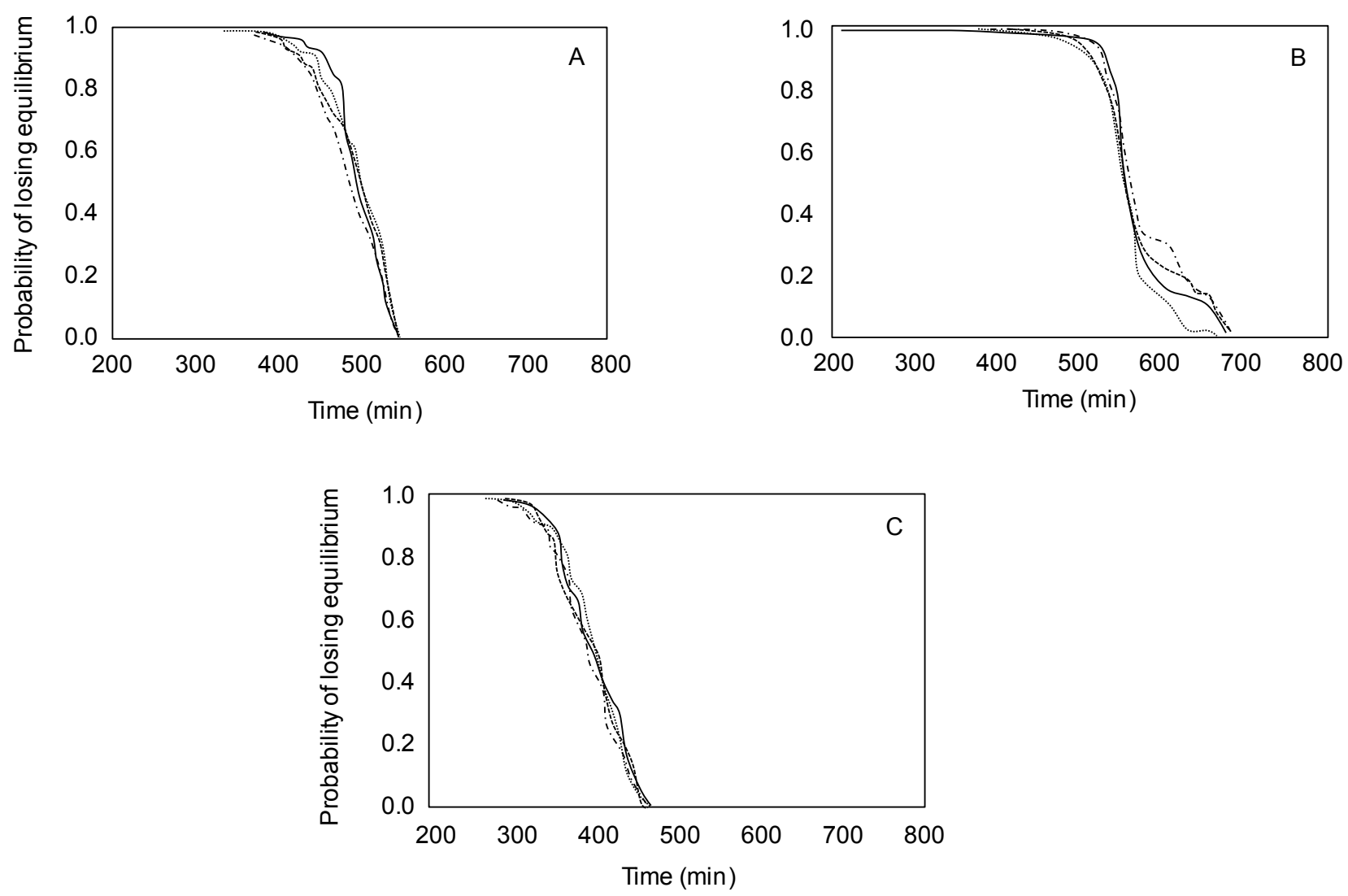
Figure 4b
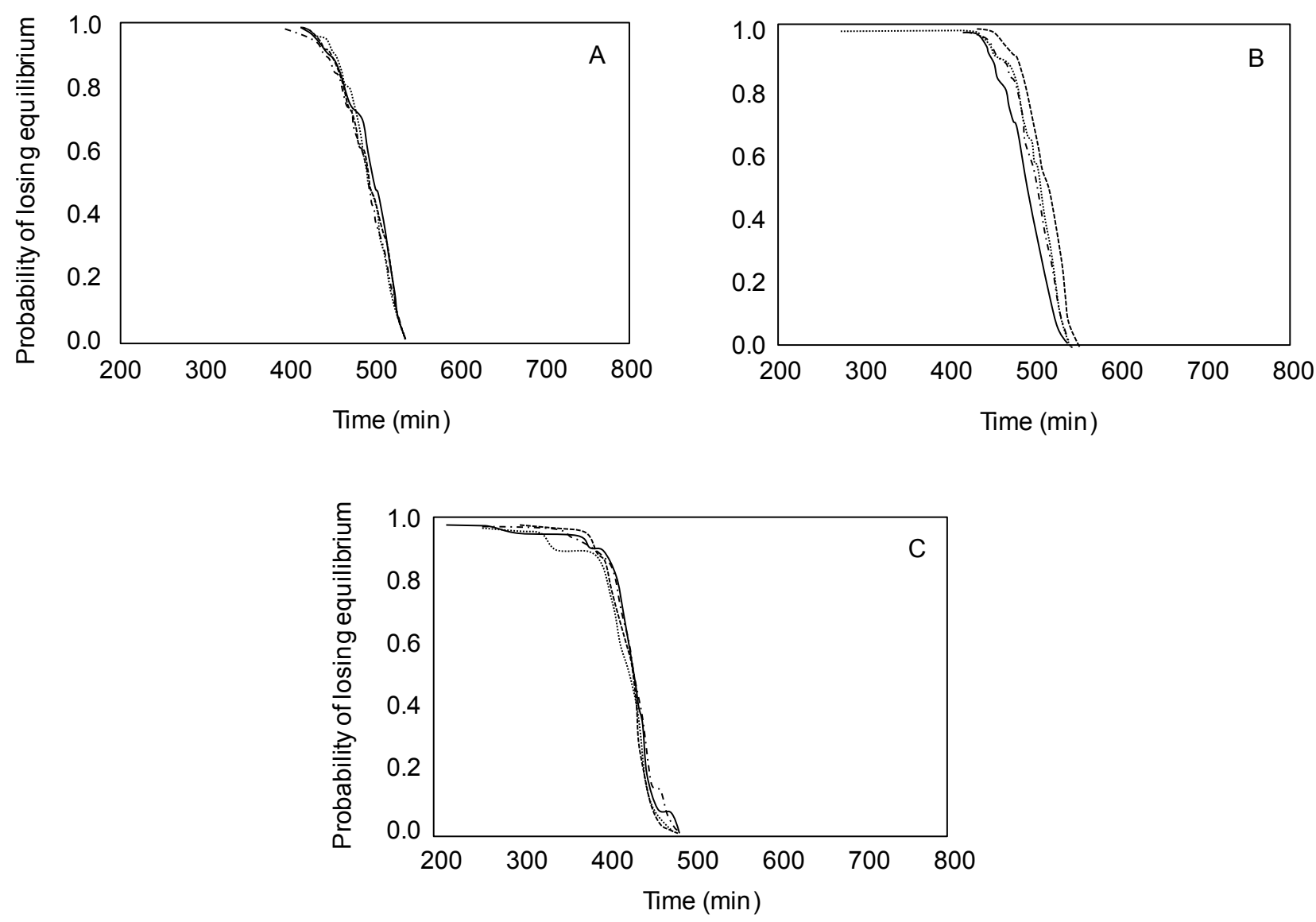

Figure 5. Salinity (close symbols) and temperature (open symbols) conditions in the earthen ponds. Measurements were made in pond \#4. Vertical dashed lines indicate pond draining and fish recovery ( $\mathrm{P} 1$ to $\mathrm{P} 4$; Table1).

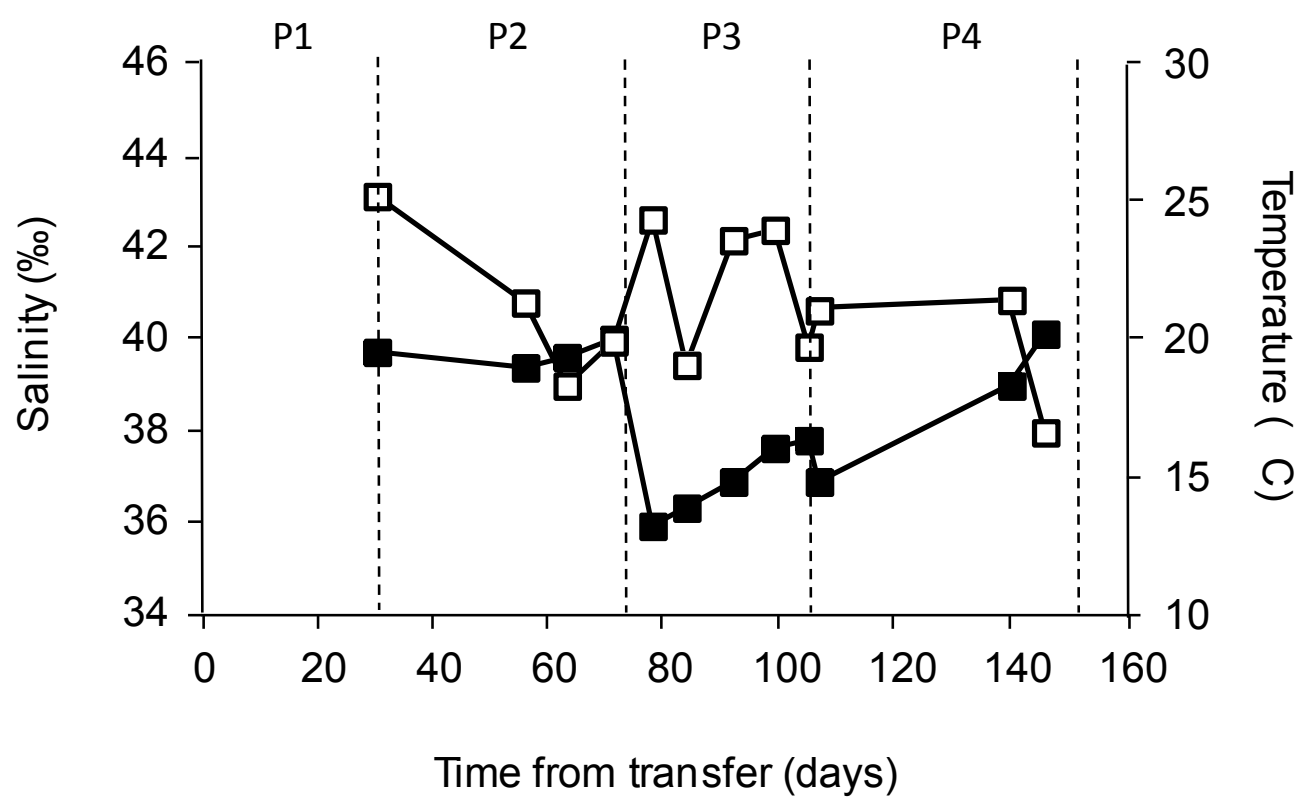


Figure 6. Relative growth rate (top panel) and survival (bottom panel) as a function of time and initial contamination exposure. White bars: P1 (May $16^{\text {th }}$ to June $17^{\text {th }}$ ); light grey bars: P2 (June $17^{\text {th }}$ to July $30^{\text {th }}$ ); dark grey bars: P3 (July $30^{\text {th }}$ to August $31^{\text {st }}$ ); black bars: P4 (August $31^{\text {st }}$ to October $14^{\text {th }}$ ); hatched bars overall experimental period (May $16^{\text {th }}$ to October $14^{\text {th }}$ ). The absence of standard error above the hatched bars for survival (bottom panel) results from the fact that fish having been regularly reallocated among ponds during the experiment, ponds are no true replicate of survival (see Materials and Methods for more details). Results from post hoc tests are also presented on the side of the figure. A line spanning two groups or periods indicates that they are not significantly different.

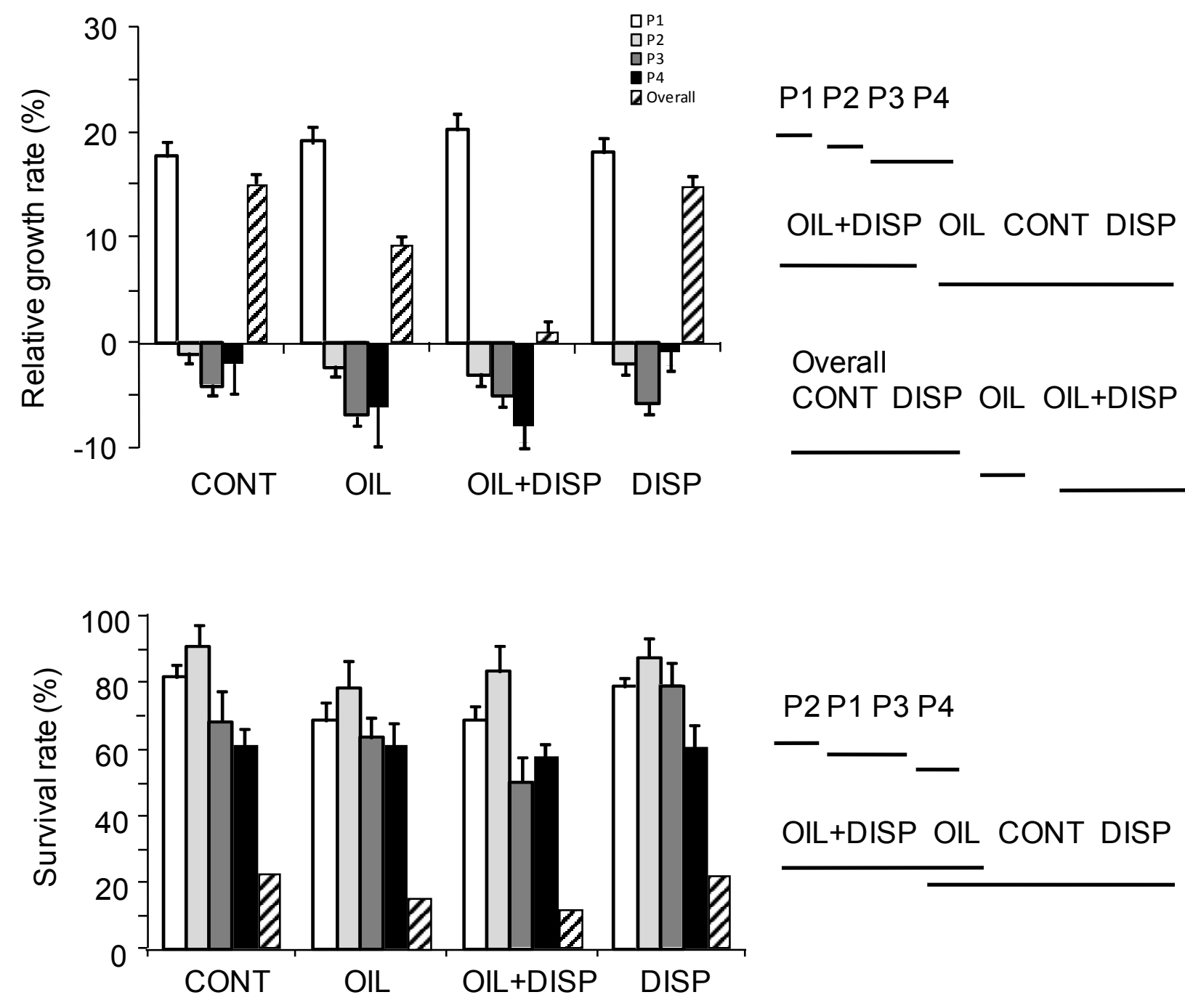


Figure 7. Relative growth during field survey period $\mathrm{P} 1$ of the non survivors (white boxes) and survivors (black boxes) of field survey periods P2, P3 and P4. An asterisk indicates a statistically significant difference between

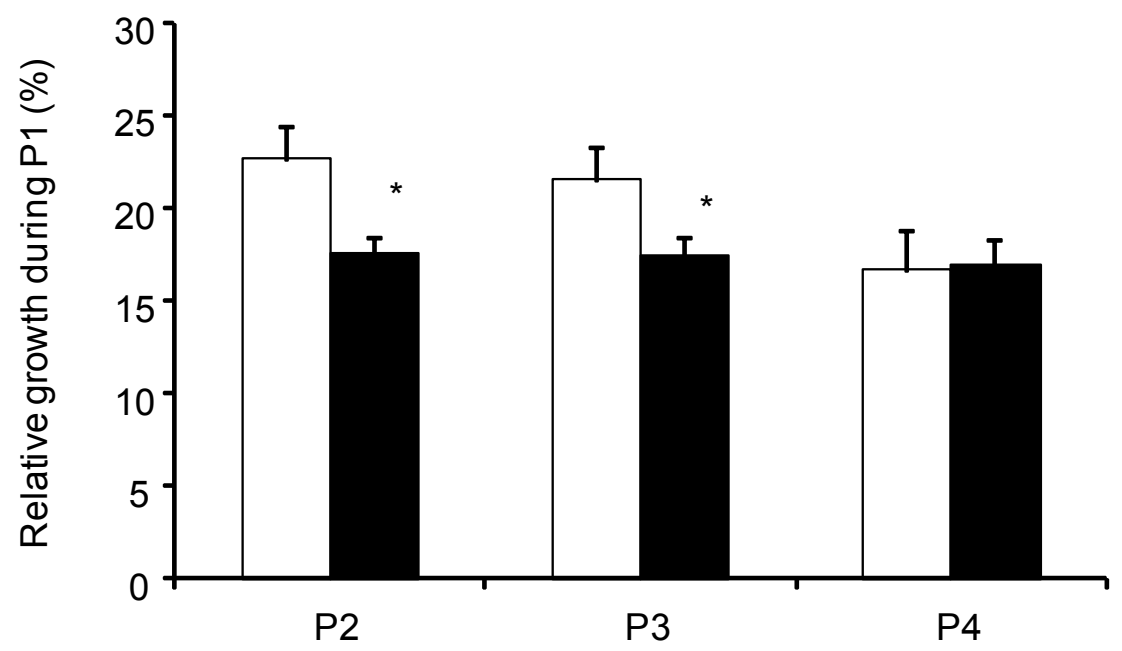

Figure 8. A posteriori analysis of hypoxia tolerance (hypoxia challenge test; top panel) and thermal sensitivity (temperature challenge test; bottom panel) of the non survivors (white boxes) and survivors (black boxes) of field survey periods P1, P2, P3 and P4. An asterisk indicates statistically significant difference between survivors and non survivors
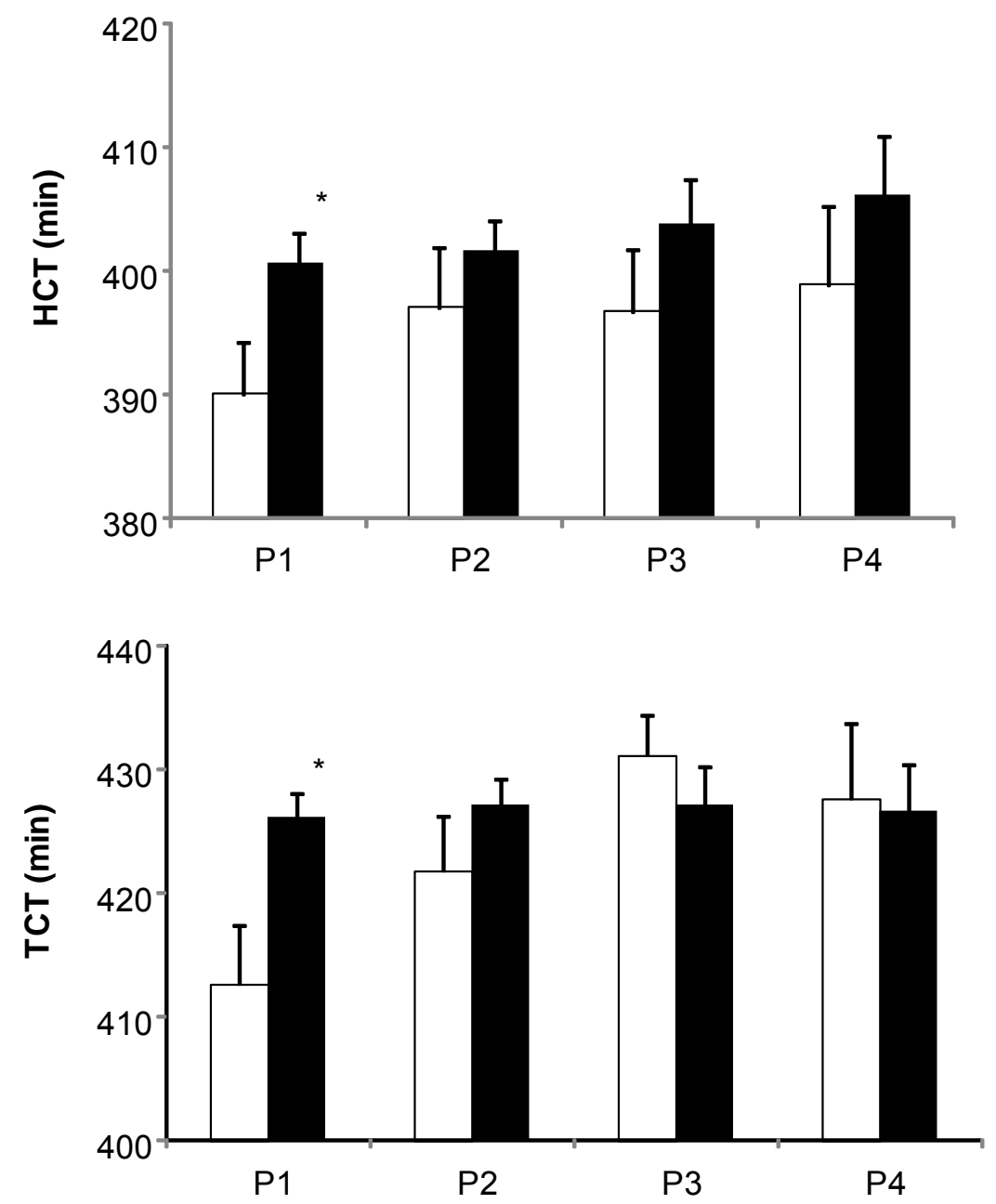